\title{
Alzheimer's phenotypes induced by overexpression of human presenilin 2 mutant proteins stimulate significant changes in key factors of glucose metabolism
}

\author{
YOUNG JU LEE ${ }^{1}$, JI EUN KIM ${ }^{1}$, IN SIK HWANG ${ }^{1}$, MOON HWA KWAK ${ }^{1}$, JAE HO LEE ${ }^{1}$, YOUNG JIN JUNG ${ }^{1}$, \\ BEUM SOO AN ${ }^{1}$, HYEOG SOONG KWON ${ }^{2}$, BYOUNG CHUL KIM ${ }^{2}$, SEON JONG KIM ${ }^{2}$, \\ JOO MAN KIM ${ }^{2}$ and DAE YOUN HWANG ${ }^{1}$
}

\begin{abstract}
Departments of ${ }^{1}$ Biomaterials Science and ${ }^{2}$ Applied IT and Engineering, College of Natural Resources and Life Sciences, Pusan National University, Miryang, Gyeongsangnam-do 627-706, Republic of Korea
\end{abstract}

Received February 1, 2013; Accepted February 20, 2013

DOI: $10.3892 / \mathrm{mmr} .2013 .1404$

\begin{abstract}
Alzheimer's disease (AD) is closely associated with significant defects in glucose metabolism. To investigate whether AD pathology induced by overexpression of human mutant presenilin 2 (PS2) protein induces changes in glucose metabolism, glucose-related factors were analyzed in the brain of 12-month-old neuron-specific enolase (NSE)/ $\mathrm{hPS} 2 \mathrm{~m}$ transgenic $(\mathrm{Tg})$ mice. NSE/hPS $2 \mathrm{~m}$ Tg mice used in this study showed AD-like phenotypes such as the accumulation of $A \beta-42$, the increase of $\gamma$-secretase activity and Tau hyperphosphorylation. A significant increase of glucose levels accompanied by a decrease of insulin levels was detected in $\mathrm{NSE} / \mathrm{hPS} 2 \mathrm{~m}$ Tg mice, while the expression levels of insulin receptors were significantly decreased in NSE/hPS2m Tg mice compared to the non-Tg littermates without affecting the insulin-like growth factor (IGF) receptor. Moreover, the levels of AKT phosphorylation involved in the downregulation of the insulin receptor signaling pathway were reduced in the brain of NSE/hPS2m Tg mice compared with non-Tg littermate, although the levels of glycogen synthase kinase 3 (GSK-3) $\beta$ phosphorylation were higher in the NSE/hPS $2 \mathrm{~m} \mathrm{Tg}$ mice compared to non-Tg littermates. Furthermore, the levels of the expression of Glut-1 and -3 were significantly reduced in the NSE/hPS2m Tg mice compared to those of control mice without affecting the Glut- 4 protein expression between the two groups of mice. In particular, the levels of the $A \beta-42$ peptide in the brain of insulin-treated NSE/hPS2m Tg mice
\end{abstract}

Correspondence to: Professor Dae Youn Hwang, Department of Biomaterials Science, College of Natural Resources and Life Sciences, Pusan National University, 50 Cheonghak-ri, Samnangjin-eup Miryang-si, Gyeongsangnam-do 627-706, Republic of Korea

E-mail: dyhwang@pusan.ac.kr

Key words: presenilin 2, insulin, insulin-receptor, AKT, GSK, glucose transporter were found to be slightly lower compared with those of the A $\beta-42$ peptide in the non-treated PS 2 transgenic mice. Thus, the data presented in this study provide strong evidence that key factors of glucose metabolism are closely associated with the AD pathology induced by the hPS $2 m$ protein, and that insulin can serve as a potential therapeutic for AD patients.

\section{Introduction}

Alzheimer's disease (AD) is one of the most common neurodegenerative disorders morpho-pathologically characterized by cellular $\mathrm{A} \beta$ amyloid plaque, intracellular neurofibrillary tangles and extensive neuronal death. Besides these pathological alterations, this disease is also associated with abnormalities in the colinergic, serotoninergic, noradrenergic and dopaminergic systems (1). These neurochemical changes may be related to the abnormal blood glucose metabolism that has been identified using positron emission tomography (2). The reduction of glucose utilization was not attributed to an insufficient supply of glucose to the brain, but rather the decrease of glucose breakdown in brain tissue $(3,4)$. Furthermore, previous studies reported that the activities of the number of enzymes and the expression of the glucose transporter involved in glucose metabolism decreased in the brain tissue of AD (5-7).

The existence of both insulin and insulin receptors in the CNS is well established (8-9). Insulin was first localized in the CNS of rats by immunohistochemical staining (10). Subsequently, the insulin mRNA was demonstrated to exist in various brain areas, suggesting that this peptide is synthesized in the brain (11). In human brain, insulin regulates enzymes associated with cerebral glucose metabolism via specific high-affinity insulin receptors, which are different from peripheral insulin receptors only in the amount of glycosylation $(12,13)$. Additionally, insulin binds to insulin-like growth factor I (IGF-I) receptors and, via these receptors, potentially exerting more generalized trophic effects on neural cell and interacting with cholinergic neurotransmission $(14,15)$. The binding of insulin to its receptor is followed by an autophosphorylation of tyrosine residues at the $\beta$-chain of the insulin receptor resulting in a subsequent activation of the intrinsic 
tyrosine kinase, which phosphorylates the first known endogenous substrate insulin-receptor substrate-1 (IRS-1) (16). Phosphorylated IRS-1 transfers its signal to a wide spectrum of cellular signal transduction pathways (17). In particular, AD patients exhibit alterations in insulin and IGF-1 levels and their receptors, leading to defective response to insulin (18).

Furthermore, the study with transgenic (Tg) 2576 mice overexpressing the Swedish mutant human amyloid precursor protein revealed an age-related cortical and hippocampal deposition of $\beta$-amyloid plaques, as well as a decreased phosphofructokinase-C (PFK-C) protein and mRNA level in cerebral cortical tissue. Additionally, 24-month-old Tg2576 mice showed reduced enzyme activity of PFK without affecting the mRNA levels of the other PFK isoforms and fructose 1,6-bisphosphatase (FBPase) in comparison to non-transgenic littermates (5). However, no studies have been conducted thus far to investigate whether the proteins involved in glucose metabolism are significantly altered in neuron-specific enolase (NSE)/hPS2m Tg mice that demonstrate AD-like pathology.

Therefore, the aim of this study was to investigate whether AD pathology induced by overexpression of human mutant PS2 protein induces changes in glucose metabolism. The findings showed that the enhancement of A $\beta-42$ peptides and $\gamma$-secretase activity in NSE/hPS2m Tg mice significantly induced the defect of glucose metabolism, including the decrease of insulin, the increase of glucose, as well as the alteration of their related receptors and the signal pathway. Furthermore, these results show that the insulin treatment may decrease the level of $A \beta-42$ peptides in the brain of NSE/ hPS2m Tg mice.

\section{Materials and methods}

Care and use of NSE/hPS2m Tg mice. NSE/hPS2m Tg mice overexpressing human mutant PS2 (hPS2m, N141I), under the control of an NSE promoter were used in this study $(19,20)$ and were obtained from the Department of Laboratory Animal Resources in Korea FAD. These Tg mice showed behavioral dysfunction, $A \beta-42$ deposition and the induction of caspase- 3 and Cox-2 activities at 12 months of age. To analyze the protein level and insulin concentration, a total of 10 mice were used; five NSE/hPS2m Tg mice and five non-Tg littermates at 12 months of age. The mice were handled in a Pusan National University-Laboratory Animal Resources Center accredited by the Korea FDA in accordance with the USA NIH guidelines (accredited unit no. 231). The mice were maintained in a specified pathogen-free environment and were housed in cages under a strict light cycle (light period for $12 \mathrm{~h}$ and dark period for $12 \mathrm{~h}$ ) and were given a standard irradiated chow diet (Purina Mills Inc., Milford, IN, USA) ad libitum.

A $\beta$-42 western blot analysis. For detection of the A $\beta-42$ level, the frozen brain of mice was sectioned with scissors and homogenized in Pro-Prep ${ }^{\mathrm{TM}}$ Protein Extraction Solution [Intron Biotechechnology Co. Ltd., Seongnam, Korea, (50 mM Tris (pH 7.4), $150 \mathrm{mM} \mathrm{NaCl}, 1 \mathrm{mM}$ DTT, $0.5 \%$ NP-40, $1 \%$ Triton X-100, 1\% deoxycholate, $0.1 \%$ SDS, proteinase inhibitor)] with a glass homogenizer. The homogenate mixture was centrifuged at $22,250 \mathrm{x}$ g for $10 \mathrm{~min}$ at $4^{\circ} \mathrm{C}$ to eliminate the nuclei and unbroken cells. The protein prepared from the brain was separated by electrophoresis in a $4-20 \%$ SDS-PAGE gel for $3 \mathrm{~h}$ and transferred to nitrocellulose membranes for $2 \mathrm{~h}$ at $40 \mathrm{~V}$. Each membrane was incubated separately with the primary anti-A $\beta-42$ antibody (MAB1560, 6E10; Chemicon International, Temecula, CA, USA) overnight at $4^{\circ} \mathrm{C}$. The membranes were washed with the washing buffer $(137 \mathrm{mM}$ $\mathrm{NaCl}, 2.7 \mathrm{mM} \mathrm{KCl}, 10 \mathrm{mM} \mathrm{Na} \mathrm{HPO}_{4}, 2 \mathrm{mM} \mathrm{KH} \mathrm{PO}_{4}$ and $0.05 \%$ Tween-20) and incubated with horseradish peroxidase-conjugated goat anti-rabbit IgG (1:1,000 dilution; Zymed, South San Francisco, CA, USA) at room temperature for $2 \mathrm{~h}$. Blots were developed using a Chemiluminescence Reagent Plus kit (ECL; Amersham Pharmacia, Piscataway, NJ, USA).

$\gamma$-secretase activity analysis. Detection of $\gamma$-secretase activity was performed according to the manufacturer's instructions (FP003; R\&D System Inc., Wiesbaden, Germany). Frozen brain tissues were sectioned with scissors and homogenized in lysis solution and $1 \mathrm{X}$ cell extraction buffer with a glass homogenizer into $0.5-2.0 \mathrm{mg} / \mathrm{ml}$ final concentrations. The homogenate was separated by centrifugation at $22,250 \mathrm{x} \mathrm{g}$ for $15 \mathrm{~min}$ at $4^{\circ} \mathrm{C}$ and then supernatant was collected for the protein and enzyme assays. Protein was assayed by the BCA method (Pierce, Rockford, IL, USA) using an ELISA reader. For the determination of $\gamma$-secretase activity, the $50 \mu \mathrm{l}$ of tissue lysate $(25-200 \mu \mathrm{g})$ prepared from the brain extract was added to each well in a 96-well microplate in triplicate and then $2 \mathrm{X}$ reaction buffer $(50 \mu \mathrm{l})$ was added. The substrate $(5 \mu \mathrm{l})$ was added to each well and the plate was incubated in the dark at $37^{\circ} \mathrm{C}$ for $1-2 \mathrm{~h}$. Fluorescence was measured at a wavelength of 335-355 nm using a Fluorescent Microplate Reader FL600 (Bio-Tek Instrument, Inc., Winooski, VT, USA).

Radioimmunoassay (RIA) and serum biochemical analyses. Blood was collected from the abdominal vein of NSE/hPS2m $\mathrm{Tg}$ mice and non-Tg littermates and then incubated at room temperature for $30 \mathrm{~min}$. The serum was separated by centrifugation at $890 \mathrm{x}$ g for $15 \mathrm{~min}$ at $4^{\circ} \mathrm{C}$. Serum insulin concentration was carried out as per the manufacturer's instructions [Coat-A-Count Insulin kit; Diagnostic Products Corp., LA, CA, USA) using a gamma counter (Cobra 5010 Quantum, Cobra 5010 II; Packard Instrument Co., Inc., Meriden, CT, USA)]. The glucose concentration was assayed according to the manufacturer's instructions by Glucose Kit using an Automatic Biochemical Analyzer (Hitachi 747, Tokyo, Japan).

Preparation of membrane protein. The brain was harvested from NSE/hPS2m and non-Tg mice. Frozen brain was sectioned with scissors and homogenized in buffer A [10 mM Tris (pH 7.4), 1 mM EDTA, 250 mM Sucrose, proteinase inhibitor (pH 7.4)] with a glass homogenizer. The homogenate mixture was centrifuged at $900 \mathrm{x} \mathrm{g}$ for $10 \mathrm{~min}$ at $4^{\circ} \mathrm{C}$ to eliminate the unbroken cells. The supernatant was transferred to a new tube and centrifuged at $110,000 \mathrm{x}$ g for $75 \mathrm{~min}$ at $4^{\circ} \mathrm{C}$ to collect the microsomal fraction. The pellet containing the microsomal fraction was resuspended in lysis buffer A containing 1\% Triton X-100 for use in the western blot analysis.

Western blot analysis. The protein prepared from the brain tissues was separated by electrophoresis in a $4-20 \%$ SDS-PAGE gel for $3 \mathrm{~h}$ and transferred to nitrocellulose 
A
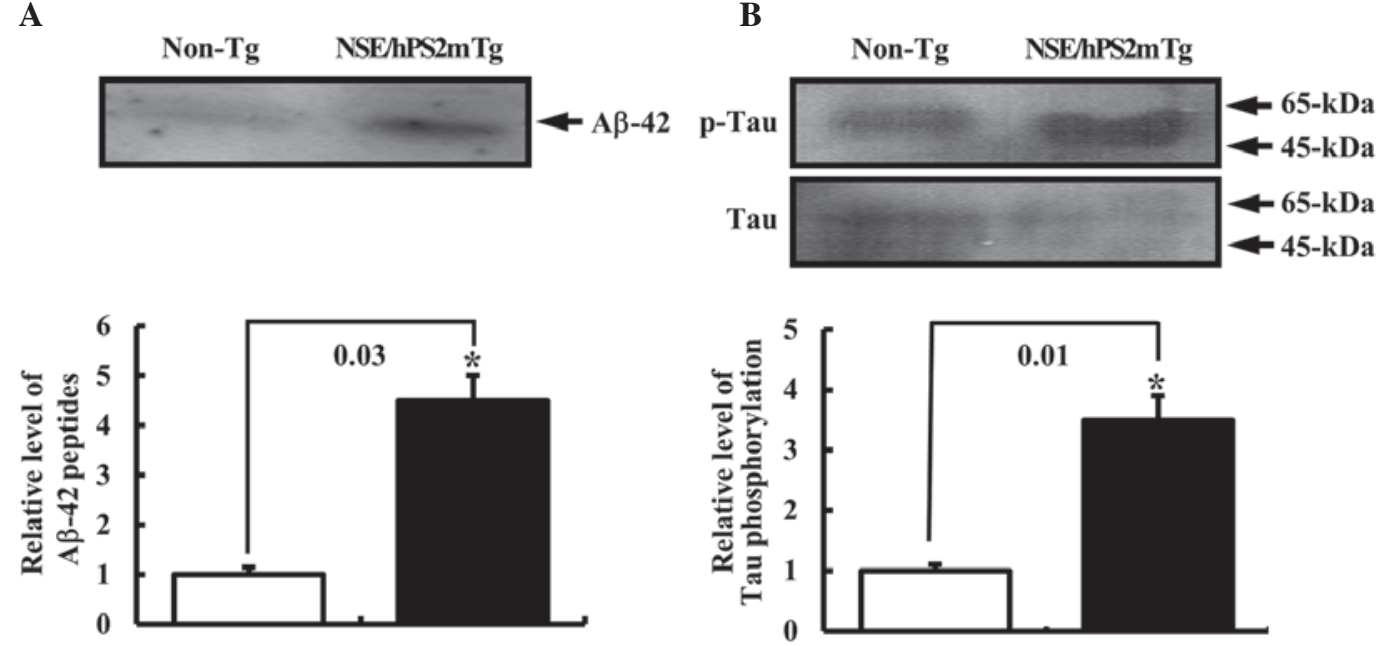

C

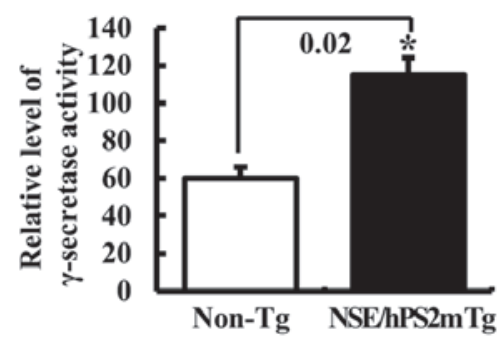

D

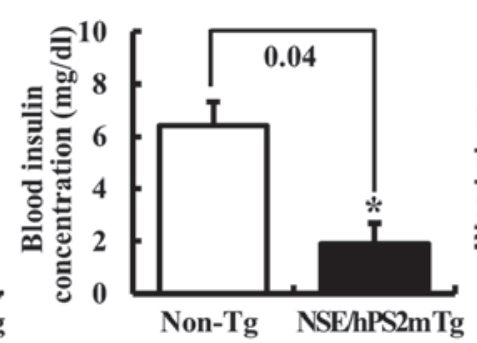

E

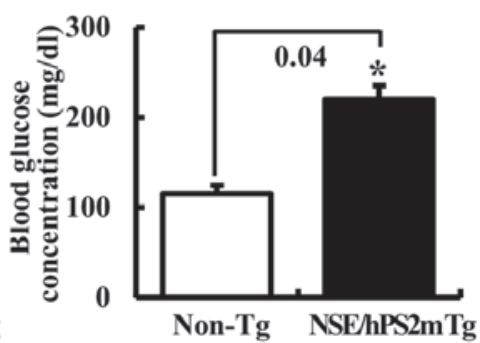

Figure 1. Characterization of AD phenotypes in the neuron-specific enolase (NSE)/hPS2m transgenic (Tg) mice. (A) Detection of A $\beta$-42 peptides. Lysates prepared from the brains were separated by $10-20 \%$ SDS-PAGE and transferred to nitrocellulose membranes. A $\beta$ - 42 levels were detected with antibodies raised against human A $\beta-42$ followed by anti-mouse-horseradish peroxidase (HRP). (B) Tau phosphorylation. The relative level of Tau phosphorylation was calculated at a rate of p-Tau level per Tau level. (C) Activity of $\gamma$-secretase. The $\gamma$-secretase activity in lysate prepared from brain extract was measured the fluorescence intensity at 335-355 nm wavelength by a Fluorescent Microplate Reader FL600. (D) Concentration of the insulin in serum. Detection of insulin concentration was performed the procedure suggested by manufacture using Coat-A-Count Insulin kit. (E) Concentration of the glucose in the plasma. Glucose concentration was assayed with Glucose kit using Automatic Biochemical Analyzer. Data are presented as the means \pm standard error of the mean (SEM) from three replicates. ${ }^{*} \mathrm{P}<0.05$, significance level compared with the non-Tg littermates.

membranes for $2 \mathrm{~h}$ at $40 \mathrm{~V}$. Each membrane was incubated separately with the primary, anti-insulin receptor $\alpha$ (sc-710; Santa Cruz Biotechnology, Inc., Santa Cruz, CA, USA), anti-insulin receptor $\beta$ (sc-711; Santa Cruz Biotechnology, Inc.), anti-IGF receptor (I7151; Sigma-Aldrich, St. Louis, MO, USA), anti-Glut-1 (sc-7903; Santa Cruz Biotechnology, Inc.), anti-Glut-3 (sc7582; Santa Cruz Biotechnology, Inc.), anti-Glut-4 (400064; Calbiochem, Darmstadt, Hesse, Germany), anti-AKT (Ab3130; Chemicon International), anti-p-AKT (Ab3132; Chemicon International), anti-GSK (9332; Cell Signaling Technology, Inc., Boston, MA, USA), anti-p-GSK (9331; Cell Signaling Technology, Inc.), anti-Tau (T7194; Sigma-Aldrich) and anti-p-Tau (T8069; Sigma-Aldrich) antibodies overnight at $4^{\circ} \mathrm{C}$. The membranes were washed with washing buffer $(137 \mathrm{mM} \mathrm{NaCl}, 2.7 \mathrm{mM}$ $\mathrm{KCl}, 10 \mathrm{mM} \mathrm{Na} \mathrm{HPO}_{4}, 2 \mathrm{mM} \mathrm{KH} \mathrm{PO}_{4}, 0.05 \%$ Tween-20) and incubated with horseradish peroxidase-conjugated goat anti-rabbit IgG (1:1,000 dilution; Zymed) at room temperature for $2 \mathrm{~h}$. Blots were developed using a Chemiluminescence Reagent Plus kit (ECL; Amersham Pharmacia).

Insulin treatments. Initially, the 12-month-old NSE/hPS2m $\mathrm{Tg}$ mice were divided into three subgroups: No-treatment group [1X phosphate-buffered saline (PBS)], low-dose group (0.2 units of insulin), high-dose group (0.4 units of insulin). Insulin (Novolin N, $100 \mathrm{IU} / \mathrm{ml}$; GreenCross, Yongin, Korea) was subcutaneously injected into NSE/hPS2m Tg mice in a volume of $0.2 \mathrm{ml}$ dilution in $1 \mathrm{X}$ PBS solution for 4 weeks.

Statistical analysis. Tests for significance between non-Tg and $\mathrm{Tg}$ mice were performed using a one-way ANOVA test of variance (SPSS for Windows, Release 10.10, standard version; SPSS, Chicago, IL, USA). Post-hoc tests of variance (SPSS for Windows, Release 10.10, standard version) were used to determine significance between insulin treatment and non-treatment $\mathrm{Tg}$ groups. Values were reported as the mean \pm standard deviation $(\mathrm{SD}) . \mathrm{P}<0.05$ was considered to indicate a statistically significant difference.

\section{Results}

Identification of AD phenotypes in NSE/hPS $2 m$ Tg mice. To detect the phenotypes of AD resulting from the overexpression of the hPS $2 m$ transgene, the A $\beta-42$ peptide and activity of $\gamma$-secretase were quantified in total brain tissue of 12-month-old $\mathrm{NSE} / \mathrm{hPS} 2 \mathrm{~m}$ Tg mice by western blot analysis and $\gamma$-secretase 
A
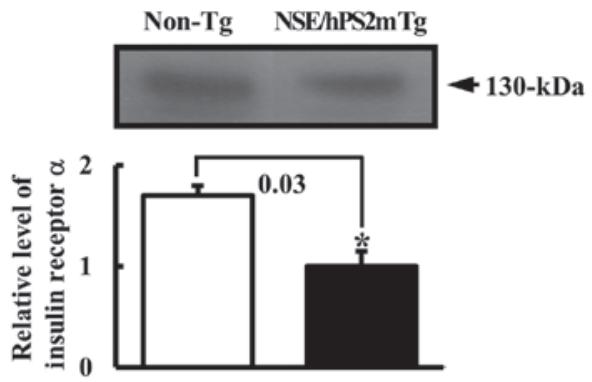

B

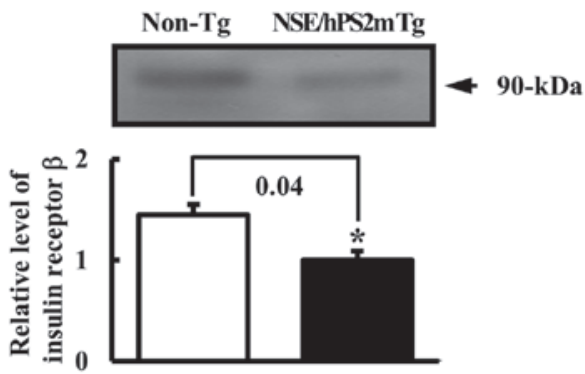

C

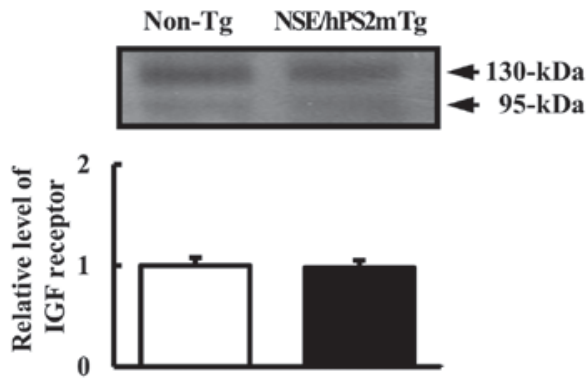

Figure 2. Expression of insulin receptor and insulin-like growth factor I (IGF-I) receptor in the brain of neuron-specific enolase (NSE)/hPS2 $\mathrm{m}$ transgenic ( $\mathrm{Tg}$ ) mice and non-Tg littermates. (A and B) Expression levels of the insulin receptor $\alpha$ and $\beta$. (C) Expression level of the IGF-1 receptor. The expression levels of three proteins in the membrane fraction prepared from the brain extract were detected with the primary anti-insulin receptor, and anti-IGF receptor antibody. Data are presented as the means \pm standard error of the mean (SEM) from three independent experiments. ${ }^{*} \mathrm{P}<0.05$, significance level compared with the non-Tg littermates.

activity assay, respectively. As shown in Fig. 1A, the level of A $\beta-42$ peptide was significantly higher in the brain of the NSE/ $\mathrm{hPS} 2 \mathrm{~m}$ Tg mice compared with that of the non-Tg littermates. Also, $\gamma$-secretase activity was significantly increased in the brain of the NSE/hPS2m Tg mice (Fig. 1C). Furthermore, the level of p-Tau (Thr 231 site) aggregated into the neurofibrillary tangle in the cytoplasm of particular pyramidal neurons was significantly increased in the brain of NSE/hPS $2 \mathrm{~m} \mathrm{Tg}$ mice (Fig. 1B). These results suggest that NSE/hPS2m Tg mice aged 12 -months possessed the AD-like phenotypes involving the deposition of $A \beta-42$, the increase of $\gamma$-secretase activity and Tau hyperphosphorylation.

Alteration of insulin and glucose levels in NSE/hPS2m Tg mice. To investigate whether cortical and hippocampal disorganization caused by $\mathrm{A} \beta-42$ peptides affected the insulin and glucose levels, insulin and glucose concentrations were measured in the serum obtained from NSE/hPS2m Tg mice.
$\mathbf{A}$

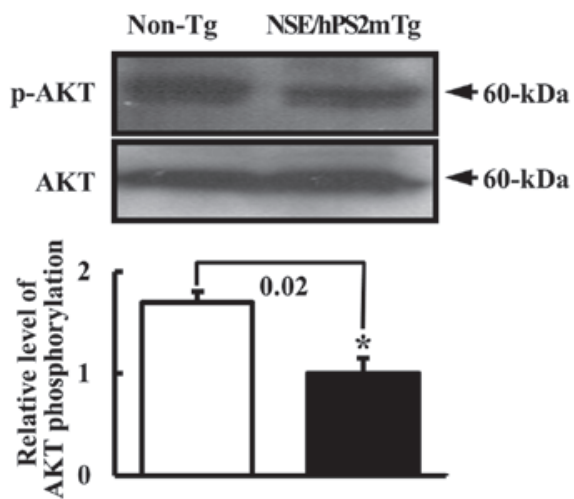

B

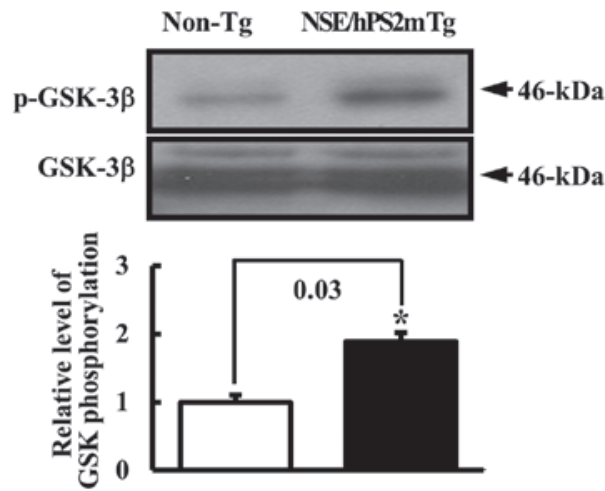

Figure 3. Phosphorylation of (A) AKT and (B) GSK in the neuron-specific enolase (NSE)/hPS2m transgenic ( $\mathrm{Tg}$ ) mice. The top panels demonstrate $40 \mu \mathrm{g}$ of protein per sample, with an antibody against phosphorated protein. The bottom panels demonstrate the total protein, which was assessed using antibodies recognizing these proteins regardless of their phosphorylated states. Data are presented as the means \pm standard error of the mean (SEM) from three independent experiments. ${ }^{*} \mathrm{P}<0.05$ is the significance level compare with the non-Tg littermates.

In the Coat-A-Count Insulin kit analysis, the concentration of insulin was significantly lower in the NSE/hPS2m Tg mice $(2.1 \mathrm{mg} / \mathrm{dl})$ than that in the non-Tg littermates $(6.2 \mathrm{mg} / \mathrm{dl})$ (Fig. 1D). By contrast, the concentration of glucose was significantly higher in the NSE/hPS2m Tg mice $(210 \mathrm{mg} / \mathrm{dl})$ compared with that in the non-Tg littermates $(120 \mathrm{mg} / \mathrm{dl})$ (Fig. 1E). Therefore, changes of the insulin and glucose concentration in $\mathrm{Tg}$ mice indicated that the deposition of $A \beta-42$ peptide was directly associated with defects in the glucose metabolism.

Differential expression of insulin receptor and IFG receptor protein in NSE/hPS2m Tg mice. To determine whether the decrease in the insulin concentration caused by $A \beta-42$ peptide affected its related receptor expression, the expression levels of the insulin receptor and IGF receptor protein were measured using western blot analysis from the membrane protein of the brain tissues. Results of the western blot analysis revealed that the expression of insulin receptors $\alpha$ and $\beta$ to be significantly reduced in the NSE/hPS2m Tg mice compared with the non- $\mathrm{Tg}$ littermates (Fig. 2A and B). However, these analyses also revealed no differences in the expression level of IGF receptors in the brain between the NSE/hPS2m Tg mice and non-Tg littermates (Fig. 2C). These results suggest that the defect in glucose regulation was capable of significantly decreasing the 
A

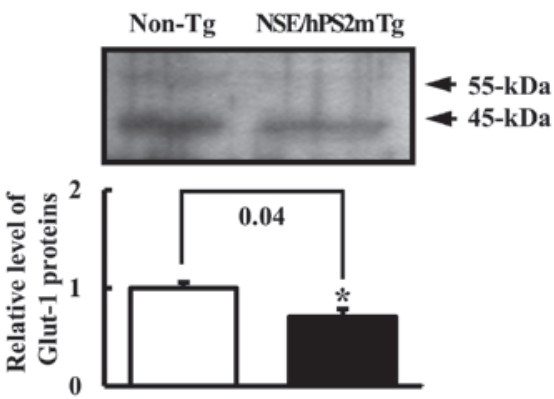

B

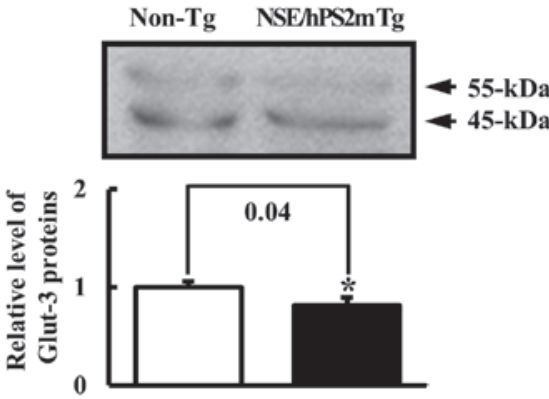

C

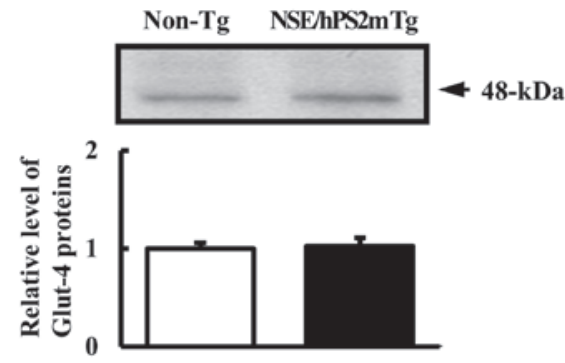

Figure 4. Expression of glucose transporters in the brain of neuron-specific enolase (NSE)/hPS2m transgenic ( $\mathrm{Tg}$ ) mice and non-Tg littermates. The expression level of (A) anti-Glut-1, (B) anti-Glut-3 and (C) anti-Glut-4 in the membrane fraction prepared from the brain extract was detected using the specific primary antibody. Glut-1 and -3 proteins were detected as two different bands of 55 and $45-\mathrm{kDa}$. Data are presented as the means \pm standard error of the mean (SEM) from three independent experiments. ${ }^{*} \mathrm{P}<0.05$, significance level compared with the non-Tg littermates.

level of insulin receptors $\alpha$ and $\beta$, although the level of IGF receptor was unaffected.

Effect of glucose regulation defect on the insulin receptor signal transduction pathway. To test the hypothesis that the defect of the glucose metabolism in the AD model would alter the phosphorylation of signal protein in the insulin receptor signal pathway, the phosphorylation rate of AKT and GSK proteins in the brain of NSE/hPS2m Tg mice was detected. AKT2 is a key signaling molecule in the insulin signaling pathway that induces glucose transport (21). Glycogen synthase kinase 3 (GSK-3) involved in the Wnt signaling cascade may be inhibited following phosphorylation by AKT (22). The level of p-AKT protein involved in the downstream signal pathway of the insulin receptor was reduced in the brain of NSE/hPS2m Tg mice compare with non-Tg littermates (Fig. 3A). By contrast, the p-GSK-3 $\beta$ level was higher in the NSE/hPS $2 \mathrm{~m}$ Tg mice than the non-Tg littermates (Fig. 3B). Thus, this result suggests that the decrease in the
A

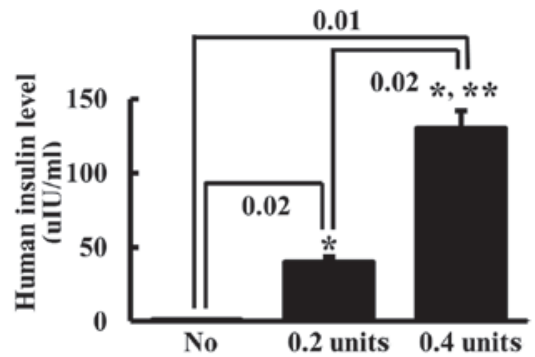

B

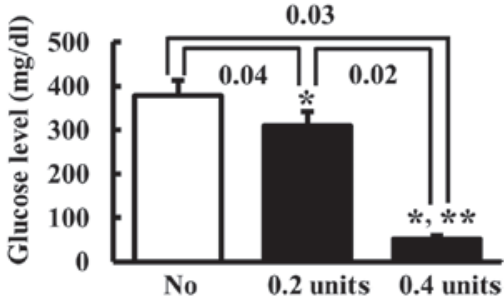

C
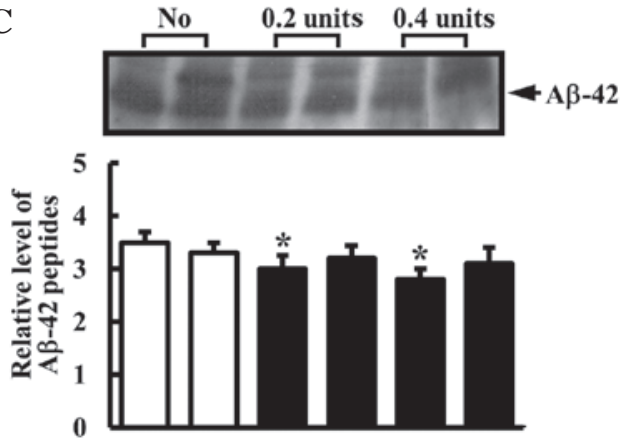

Figure 5. Effect of insulin administration on the $A \beta-42$ peptide in the neuron-specific enolase (NSE)/hPS2 $\mathrm{m}$ transgenic (Tg) mice. The NSE/hPS2m $\mathrm{Tg}$ mice were treated with 0.2 or 0.4 units of insulin for 4 weeks, while the control group were treated with $1 \mathrm{X}$ PBS solution for the same period of time. (A) The insulin level in serum was assayed with radioimmunoassay, (B) while the glucose levels were assayed with serum biochemical analysis. (C) The levels of $A \beta-42$ peptides were detected with anti-A $\beta-42$ antibody in the brain extracts from insulin-treated and non-treated Tg mice. Data are the means \pm standard error of the mean (SEM) from three independent experiments. ${ }^{*} \mathrm{P}<0.05$, significance level compared with the no-treated group. ${ }^{* *} \mathrm{P}<0.05$, significance level compared to the 0.2 units-treated group.

insulin receptors $\alpha$ and $\beta$ significantly induced the change of signal protein activation in the downstream signal pathway of the insulin receptor, respectively.

Differential expression of glucose transporter in NSE/ hPS $2 \mathrm{~m} \mathrm{Tg} \mathrm{mice.} \mathrm{To} \mathrm{determine} \mathrm{whether} \mathrm{the} \mathrm{decrease} \mathrm{of} \mathrm{the}$ glucose level affected the expression of glucose transporter, western blot analysis was performed to detect the expression level of the glucose transporter in the membrane protein of mice brains. Fig. 4 shows the differences in the distribution of various molecular mass forms of Glut-1 and -3 in total cerebral homogenate. Two discrete bands at $45-$ and $55-\mathrm{kDa}$ are observed in total homogenate. The density of the 45- and $55-\mathrm{kDa}$ band in Glut-1 was significantly reduced in NSE/ hPS $2 \mathrm{~m} \mathrm{Tg}$ mice compared with that of non-Tg littermates (Fig. 4A). The 45-kDa band in Glut-3 was significantly reduced in the NSE/hPS2m Tg mice when this level was compared 
with non-Tg littermates. However, the density of the $55-\mathrm{kDa}$ band was not significantly different between the NSE/hPS2m Tg and control mice (Fig. 4B). By contrast, there was no difference in the Glut-4 protein level between the NSE/hPS $2 \mathrm{~m} \mathrm{Tg}$ mice and non-Tg littermates (Fig. 4C). These results suggest that the defect of glucose regulation may be attributed to the decrease in the expression level of Glut-1 and -3 proteins, but not for Glut-4.

Effect of insulin administration on the deposition of the A $\beta-42$ peptide. Previously, Boyt et al (23) suggested that glucose ingestion and the subsequent elevation of plasma concentration of glucose and insulin lead to a decrease in the level of amyloid precursor protein in plasma. Therefore, to examine whether treatment of insulin in the NSE/hPS $2 \mathrm{~m} \mathrm{Tg}$ mice affected the concentration of the $A \beta-42$ peptide, the insulin was injected into 12-month-old Tg mice. In RIA and serum biochemical analysis, the insulin concentration was significantly higher in the serum of insulin-treated mice than that of non-treated $\mathrm{Tg}$ mice. However, the glucose concentration in the insulin-treated mice was 3-4-fold lower than in the non-treated $\mathrm{Tg}$ mice, respectively (Fig. 5A). Furthermore, the western blot analysis revealed that the level of $A \beta-42$ peptide in the brain of the insulin-treated mice was slightly reduced compare with that of non-treated mice (Fig. 5B). Altering the level of $A \beta-42$ peptide from insulin-treated mice as shown by western blot analysis, suggests the possibility that insulin treatment is directly associated with a decrease in the $\mathrm{A} \beta-42$ peptide (Fig. 5C).

\section{Discussion}

One of the key functional disturbances in AD is the reduction in glucose utilization, which may be related to the increased A $\beta-42$ peptide deposition that occurs in the neocortical region and in walls of cerebral blood vessels. Glucose metabolism is important in brain disorders, as glucose is the energy source in the brain. In addition, the reduction in insulin concentration could induce disturbing glucose metabolism (24-26). Therefore, the present study was conducted with NSE/hPS2m $\mathrm{Tg}$ mice and non-Tg mice to observe the correlation between the $\beta$-amyloid peptide and glucose metabolism in the brain. A significant behavioral dysfunction in the water maze test and the levels of $\mathrm{A} \beta-42$, caspase- 3 and Cox- 2 expression were especially observed in the brains of NSE/hPS $2 \mathrm{~m}$ Tg mice at 12-months of age (19). These $\mathrm{Tg}$ mice showed a $40-50 \%$ increase in the $\mathrm{A} \beta-42$ peptide and $\gamma$-secretase activity from their brains at 12-months of age (Fig. 1A and B). A previous study reported that the NSE/hPS $2 \mathrm{~m}$ Tg mice developed a greater number of fibrillar $\mathrm{A} \beta$ deposits in the cortex and hippocampus than the non-Tg littermates (27). Furthermore, our results suggest that the NSE/hPS $2 \mathrm{~m}$ Tg mice used in this study exhibit AD-like phenotypes at 12-months of age.

Insulin is derived from a common precursor, proinsulin, from which these peptides are released in equimolar amounts by proteolytic cleavage (28). Insulin and $\mathrm{A} \beta$ peptide are also common substrates for insulin-degrading enzyme (29), which is activated in various tissues including brain tissues (30) and may be important in eliminating toxic amyloidogenic peptides $(31,32)$. It has been demonstrated by cell culture and animal experiments that insulin in the brain potently effects neuronal glucose metabolism and cell differentiation $(12,33)$. In our study, the level of insulin and its receptor between $\mathrm{NSE} / \mathrm{hPS} 2 \mathrm{~m}$ Tg mice and non-Tg littermates were determined to examine whether the incidence of $\mathrm{AD}$ was able to affect the glucose metabolism pathway. RIA revealed that insulin concentration was significantly reduced in the NSE/hPS $2 \mathrm{~m}$ $\mathrm{Tg}$ mice compared with the non-transgenic mice. In addition, the expression of insulin receptor $\alpha$ and $\beta$ chain decreased in the brain of the NSE/hPS2m Tg mice compared with that of the non-Tg littermates. With respect to insulin receptors in NSE/hPS2m Tg mice, we have, to the best of our knowledge, shown for the first time that the expression of insulin receptors increased in the brain of NSE/hPS $2 \mathrm{~m}$ Tg mice thereby increasing the $A \beta-42$ peptides by the overexpression of the mutant PS2 gene under the control neuron-specific promoter. We have also confirmed IGF-I receptor expression in the NSE/hPS2m Tg mice, as shown earlier in AD patients $(18,34,35)$. The densities of these neurotrophic receptors were unchanged in NSE/hPS $2 \mathrm{~m} \mathrm{Tg}$ mice in contrast to the insulin receptor. These results provide further evidence for specific involvement of brain insulin receptors in the pathogenesis of AD.

Additionally, insulin binds to IGF receptors and, via its receptor, possibly exerts more generalized trophic effects on neural cells and interaction with cholinergic neurotransmission $(14,15)$. The binding of insulin to its receptor is followed by the autophosphorylation of tyrosine residues at the $\beta$-chain of insulin receptor resulting in subsequent activation of the intrinsic tyrosine kinase, which phosphorylates the initial endogenous substrate IRS-1 (16). Phosphorylated IRS-1 transfers signals to a wide spectrum of cellular signal transduction pathways (17). In the AD patients, the activation of AKT was decreased in the signaling pathway of insulin receptor downstream. By contrast, it was reported that the GSK-3 $\beta$ and Tau protein on the downstream of AKT protein were significantly activated in the brains of AD patients compared with the age-matched controls (36). Our results have shown that the phosphorylated AKT protein significantly decreased in the brains of NSE/hPS2m Tg mice compared with non-Tg littermates, while activated GSK-3 and Tau significantly increased. These observations suggest that expression of the hPS $2 \mathrm{~m}$ transgene might accelerate the pathogenic changes in glucose metabolism defect, through an AKT, a GSK-3 and a Tau phosphorylation, either directly or indirectly for underlying AD.

Findings of previous studies have shown decreased protein levels involved in glucose metabolism in AD patient brains. In senile dementia of Alzheimer type, the concentration of plasma glucose resulted in a significant increase compared with the age-matched control group $(37,38)$. Significantly decreased cortical glucose transporter subtype (Glut-1 and Glut-3) was identified in the brain of AD patients compared with the age-matched controls $(6,7,39)$. Glut-1 and -3 are expressed the major glucose transporter in the brain. Glut-1 can be detected as two molecular mass forms of 45- and $55-\mathrm{kDa}$, which differ in their extent of glycosylation (40). Our data have identified reduced Glut- 1 and 3 proteins in the brain of NSE/hPS2m Tg mice, while no difference was observed in the Glut- 4 protein level. Furthermore, the density of the 
45- and 55-kDa bands in Glut-1 was significantly reduced in $\mathrm{NSE} / \mathrm{hPS} 2 \mathrm{~m} \mathrm{Tg}$ mice compared with controls. The $55-\mathrm{kDa}$ band in Glut-3 was significantly reduced in the NSE/hPS2m $\mathrm{Tg}$ mice compared to the non-Tg littermates. However, the density of the 45-kDa bands was not significantly different between the NSE/hPS2m Tg mice and non-Tg littermates. These results suggest the defect of glucose metabolism in the brain of NSE/hPS $2 \mathrm{~m} \mathrm{Tg}$ mice is significantly associated with the lower expression of the Glut-1 and -3 proteins, but not with Glut-4.

We also examined the effect of insulin on the deposition of A $\beta-42$ peptides in the brain. Previous studies have suggested that the subsequent elevation of plasma insulin leads to a decrease in plasma amyloid precursor protein concentration $(23,41)$. In this study, when the NSE/hPS2m Tg mice were treated with insulin by subcutaneous injection for 4 weeks, the level of the $A \beta-42$ peptide was slightly decreased in the treated NSE/hPS2m Tg mice compared with the non-treated $\mathrm{NSE} / \mathrm{hPS} 2 \mathrm{~m}$ Tg mice. This observation suggests that insulin is important in $A \beta-42$ peptide degradation processing, although the nature of this role and the specific mechanisms remain to be elucidated. Therefore, more studies are required to investigate the detailed mechanism for the correlation between the insulin concentration and amyloid precursor protein and the clinical significance of the physiological changes in the insulin treatment condition.

\section{Acknowledgements}

We would like to thank Dr Jun Yong Cho at the Korea National Sport University for consulting of glucose metabolism analyses. This study was supported by the 2012 Specialization Project Research Grant funded by the Pusan National University.

\section{References}

1. Gsell W, Moll G, Sofic E and Riederer P: Cholinergic and monoaminergic neurotransmitter systems in patients with Alzheimer's disease and senile dementia of Alzheimer type: a clinical evaluation. In: Dementias-neurochemistry, neuropathology, neuroimaging, neuropsychology and genetics. Maurer K (ed). Braunschweig, Vieweg, pp25-51, 1993.

2. Hoyer S: Senile dementia and Alzheimer's disease. Brain blood flow and metabolism. Prog Neuropsychopharmacol Biol Psychiatry 10: 447-478, 1986.

3. Hoyer S, Oesterreich K and Wanger O: Glucose metabolism as the site of the primary abnormality in early-onset dementia of Alzheimer type? J Neurol 235: 143-148, 1988.

4. Hoyer S, Nitsch R and Oesterreich K: Predominant abnormality in cerebral glucose utilization in late-onset dementia of the Alzheimer type: a cross-sectional comparison against advanced late-onset and incipient early-onset cases. J Neural Transm Park Dis Dement Sect 3: 1-14, 1991.

5. Bigl M, Apelt J, Eschrich K and Schliebs R: Cortical glucose metabolism is altered in aged transgenic $\mathrm{Tg} 2576$ mice that demonstrate Alzheimer plaque pathology. J Neural Transm 110: 77-94, 2003.

6. Mooradian AD, Chung HC and Shah GN: Glut-1 expression in the cerebral of patients with Alzheimer's disease. Neurobiol Aging 18: 469-474, 1997.

7. Simpson IA, Chundu KR, Davies-Hill T, Honer WG and Davies P: Decreased concentrations of Glut1 and Glut3 glucose transporters in the brains of patients with Alzheimer's disease. Ann Neurol 35: 546-551, 1994.

8. Baskin DG, Wilcox BJ, Figlewicz DP and Dorsa DM: Insulin and insulin-like growth factors in the CNS. Trends Neurosci 11: $107-111,1988$.
9. Wozniak M, Rydzewski B, Baker SP and Raizada MK: The cellular and physiological actions of insulin in the central nervous system. Neurochem Int 22: 1-10, 1993.

10. Harvankova J, Schmerchel D, Roth $\mathrm{J}$ and Brownstein $\mathrm{M}$ : Identification of insulin in rat brain. Proc Natl Acad Sci USA 75: 5737-5741, 1978.

11. Devasker SU, Giddings SJ, Rajakumar PA, Carnaghi LR, Menon RK and Zahm DS: Insulin gene expression and insulin synthesis in mammalian neuronal cells. J Biol Chem 269: 8445-8454, 1994.

12. Hoyer S, Prem L, Sorbi S and Amsucci L: Stimulation of glycolytic key enzymes in cerebral cortex by insulin. Neuroreport 4: 991-993, 1993

13. de Pablo F and de la Rosa E: The developing CNS: a scenario for the action of proinsulin, insulin and insulin-like growth factors. Trends Neurosci 18: 143-150, 1995.

14. Calissano P, Ciotti MT, Battistini L, Zona C, Angelini A, Merlo D and Mercanti D: Recombination insulin-like growth factor I exerts a trophic action and confers glutamate sensitivity on glutamate-resistant cerebellar cells. Proc Natl Acad Sci USA 90: 8752-8756, 1993.

15. Quirion R, Araujo DM, Lapehak PA, Seto D and Chabot JG: Growth factors and lymphokines: modulators of cholinergic neuronal activity. Can J Neurol Sci 18: 390-393, 1991

16. Sun XJ, Rothenberg P, Kahn CR, Backer JM, Araki E, Wilden PA, Cahill DA, Goldstein BJ and White MF: Structure of the insulin receptor substrate ISR-1 defines a unique signal transduction protein. Nature 352: 73-77, 1991.

17. White MF and Kahn CR: The insulin signaling system. J Biol Chem 269: 1-4, 1994.

18. Frolich L, Blum-Degen D, Bernstein HG, Engelsberger S, Humrich J, Laufer S, Muschner D, Thalheimer A, Turk A, Hoyer S, Zochling R, Boissle KW, Jellinger K and Riederer P: Brain insulin and insulin receptors in aging and sporadic Alzheimer's disease. J Neural Transm 105: 423-438, 1998.

19. Hwang DY, Chae KR, Kang TS, Hwang JH, Lim CH, Kang HK, Goo JS, Lee MR, Lim HJ, Min SH, Cho JY, Hong JT, Song CW, Paik SG, Cho JS and Kim YK: Alterations in behavior, amyloid $\beta-42$, caspase-3, and Cox-2 in mutant PS2 transgenic mouse model of Alzheimer's disease. FASEB J 16: 805-813, 2002.

20. Hwang DY, Cho JS, Oh JH, Shim SB, Jee SW, Lee SH, Seo SJ, Lee SK, Lee SH and Kim YK: Differentially expressed genes in transgenic mice carrying human mutant presenilin-2 (N141I): correlation of selenoprotein $\mathrm{M}$ with Alzheimer's disease. Neurochem Res 30: 1009-1019, 2005.

21. Garofalo RS, Orena SJ, Rafidi K, Torchia AJ, Stock JL, Hildebrandt AL, Coskran T, Black SC, Brees DJ, Wicks JR, McNeish JD and Coleman KG: Severe diabetes, age-dependent loss of adipose tissue, and mild growth deficiency in mice lacking Akt2/PKB beta. J Clin Invest 112: 197-208, 2003.

22. Meijer L, Flajolet M and Greengard P: Pharmacological inhibitors of glycogen synthase kinase 3. Trends Pharmacol Sci 25: 471-480, 2004

23. Boyt AA, Taddei TK, Hallmayer J, Helmerhorst E, Gandy SE, Craft S and Martins RN: The effect of insulin and glucose on the plasma concentration of Alzheimer's amyloid precursor protein. Neuroscience 95: 727-734, 2000.

24. Meier-Ruge WA and Bertoni-Freddari C: Pathogenesis of decreased glucose turnover and oxidative phosphorylation in ischemic and trauma-induced dementia of the Alzheimer type. Ann N Y Acad Sci 826: 229-241, 1997.

25. Hoyer S: Brain glucose and energy metabolism abnormalities in sporadic Alzheimer disease. Causes and consequences: an update. Exp Gerontol 35: 1363-1372, 2000.

26. Hoyer S: The brain insulin signal transduction system and sporadic (type II) Alzheimer disease: an update. J Neural Transm 109: 341-360, 2002.

27. Oyama F, Sawamura N, Kobayashi K, Morishima-Kawashima M, Kuramochi T, Ito M, Tomita T, Maruyama K, Saido TC, Iwatsubo T, Capell A, Walter J, Grunberg J, Ueyama Y, Haass C and Ihara Y: Mutant presenilin 2 transgenic mouse: effect on an age-dependent increase of amyloid beta-protein 42 in the brain. J Neurochem 71: 313-322, 1998.

28. Polonsky KS and Rubenstein AH: C-peptide as a measure of the secretion an hepatic extraction of insulin. Pitfalls and limitations. Diabetes 33: 486-494, 1984.

29. Kurochkin IV and Goto S: Alzheimer's beta-amyloid peptide specifically interacts with and is degraded by insulin degrading enzyme. FEBS Lett 345: 33-37, 1994. 
30. Authier F, Posner BI and Bergeron JJ: Insulin-degrading enzyme. Clin Invest Med 19: 149-160, 1996.

31. Perez A, Morelli L, Cresto JC and Castano EM: Degradation of soluble amyloid beta-peptides 1-40, 1-42, and the Dutch variant 1-40Q by insulin degrading enzyme from Alzheimer disease and control brains. Neurochem Res 25: 247-255, 2000.

32. Vekrellis K, Ye Z, Qui WQ, Walsh D, Hartley D, Cheseneau V, Rosner MR and Selkoe DJ: Neurons regulate extracellular levels of amyloid-protein via proteolysis by insulin-degrading enzyme. J Neurosci 20: 1657-1665, 2000.

33. Henneberg N and Hoyer S: Short-term or long-term intracerebroventricular (i.c.v) infusion of insulin exhibits a discrete anabolic effect on cerebral energy metabolism in the rat. Neurosci Lett 175: 153-156, 1994

34. De Keyser J, Wilczak N and Goosens A: Insulin-like growth factor-1 receptor densities in human frontal cortex and white matter during aging, in Alzheimer's disease, and in Huntington's disease. Neurosci Lett 172: 93-96, 1994.

35. Crew FT, McElhaney R, Freund G, Ballinger WE Jr and Raizada MK: Insulin-like growth factor I receptor binding in brains of Alzheimer's and alcoholic patients. J Neurochem 58: 1205-1210, 1992.

36. Stein TD and Johnson JA: Lack of neurodegeneration in transgenic mice overexpressing mutant amyloid precursor protein is associated with increased level of transthyretin and the activation of cell survival pathways. J Neurosci 22: 7380-7388, 2002.
37. Craft S, Dagogo-Jack SE, Wiethop BV, Murphy C, Nevins R, Fleschman S, Rice V, Newcomber JW and Cryer PE: Effects of hyperglycemia on memory and hormone levels in dementia of the Alzheimer type: a longitudinal study. Behav Neurosci 107: 926-940, 1993.

38. Manning CA, Ragozzino ME and Gold PE: Glucose enhancement of memory in patients with probable senile dementia of the Alzheimer's type. Neurobiol Aging 14: 523-528, 1993.

39. Harr SD, Simonian NA and Hyman BT: Functional alterations in Alzheimer's disease: decreased glucose transporter 3 immunoreactivity in the perforant pathway terminal zone. J Neuropathol Exp Neurol 54: 38-41, 1995.

40. Sivitz WS, DeSautel PS and Pessin JE: Regulation of the glucose transporter in developing rat brain. Endocrinology 124: 1875-1880, 1989.

41. Craft S, Asthana S, Cook DG, Baker LD, Cherrier M, Purganan K, Wait C, Petrova A, Latendresse S, Watson GS, Newcomer JW, Schellenberg GD and Krohn AJ: Insulin dose-response effects on memory and plasma amyloid precursor protein in Alzheimer's disease: interactions with apolipoprotein E genotype. Psychoneuroendocrinology 28: 809-822, 2003. 